\title{
Recanalization of a complete coloanal anastomotic obstruction using a combined antegrade-retrograde rendezvous technique
}

A 66-year-old man with a history of lower rectal adenocarcinoma and robotic-assisted low anterior resection with creation of a diverting ileostomy, presented with complete stenosis of the coloanal anastomosis ( $\triangleright$ Fig.1 a). Rendezvous recanalization of the coloanal obstruction was planned ( $\triangleright$ Video 1 ).

A pediatric colonoscope was advanced through the ileostomy toward the distal colon where complete obstruction was identified at the coloanal anastomosis ( Fig. 1 b). As the colonoscope could not be advanced to the blind end, the blunt end of an injection needle was used to push at the blind end to facilitate identification of the puncture site ( $\mathbf{F i g} \cdot \mathbf{2 a}$ ). Using transillumination and digital palpation, the coloanal anastomosis was punctured from the anal side using a trocar ( Fig. 2 b). A 0.035-inch Jagwire (Boston Scientific, Marlborough, Massachusetts, USA) was advanced through the trocar and captured using a snare. The guidewire was pulled out and both ends of the guidewire were captured. The coloanal stricture was dilated using a controlled radial expansion balloon ( $\mathbf{F i g} \cdot \mathbf{3 a}$ ). An $18 \times 153-\mathrm{mm}$ esophageal fully covered metal stent was advanced from the anal side and deployed across the coloanal stricture ( $\mathbf{F i g} \mathbf{3} \mathbf{3 b}$ ). The stent was secured with two 2-0 silk sutures. To maintain patency of the anastomosis in the event of stent migration, a colonic decompression tube was advanced over the guidewire and both ends were sutured together. Computed tomography scan confirmed correct position of the stent (-Fig.4).

Sigmoidoscopy was performed at 4 weeks for stent removal. The anastomosis was patent and had healed ( $\mathbf{F i g . 5}$ ). lleostomy reversal was successfully performed 5 days later.

Rendezvous recanalization of complete coloanal obstruction is a potential alter-
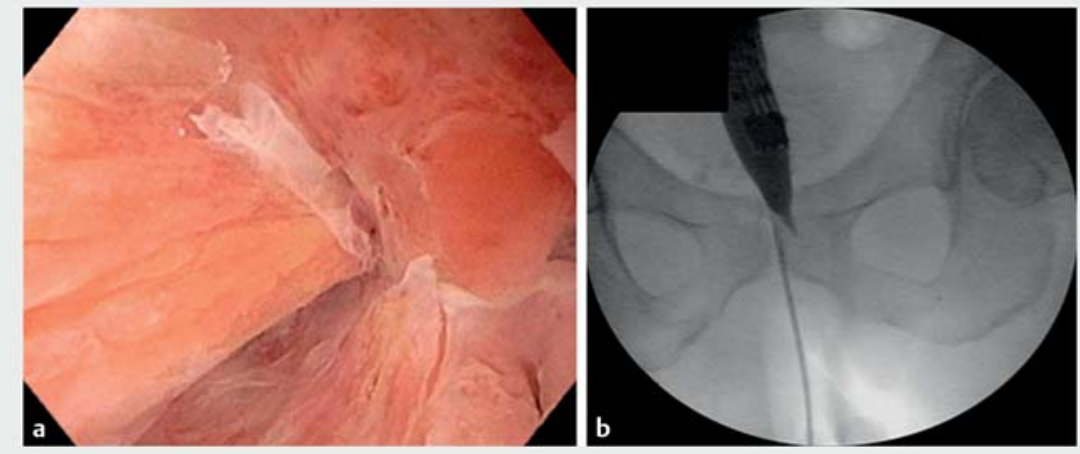

- Fig. 1 Initial imaging. a Sigmoidoscopy showed complete obstruction at the coloanal anastomosis. b Fluoroscopy during the procedure showed luminal narrowing and complete obstruction at the coloanal anastomosis.

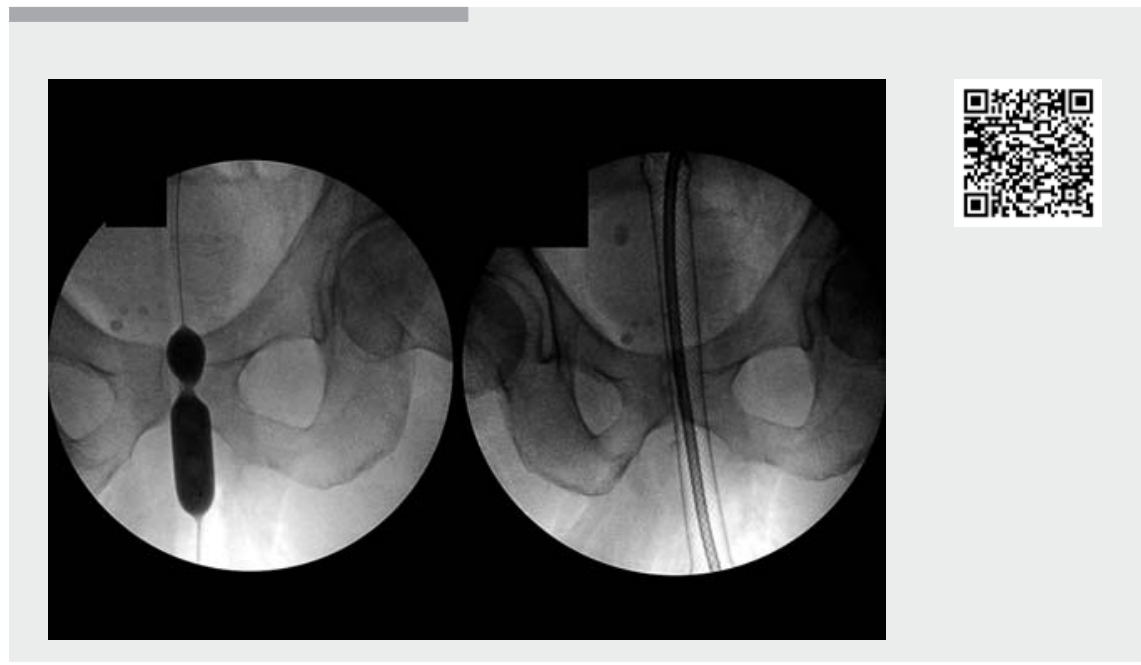

Video 1 Recanalization of a complete coloanal anastomotic obstruction using a combined antegrade-retrograde rendezvous technique.

native to revision surgery, which is difficult and has high morbidity. When endoscopic ultrasound-guided techniques for accessing the proximal colon are not possible, combination of transillumination and digital palpation is a viable option.

Endoscopy_UCTN_Code_TTT_1AQ_2AF

\section{Competing interests}

Dr. Ngamruengphong is a consultant for Boston Scientific. All other authors declare that they have no competing interests. 


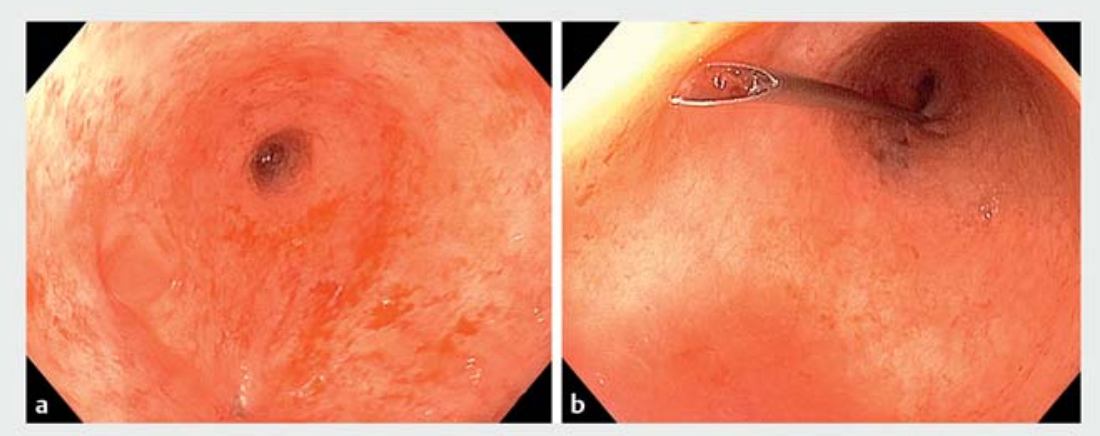

- Fig. 2 Colonoscopic views. a The blunt end of an injection needle was used to push at the blind end to facilitate identification of the puncture site. $\mathbf{b}$ A trocar was used to puncture the coloanal anastomosis from the anal side.
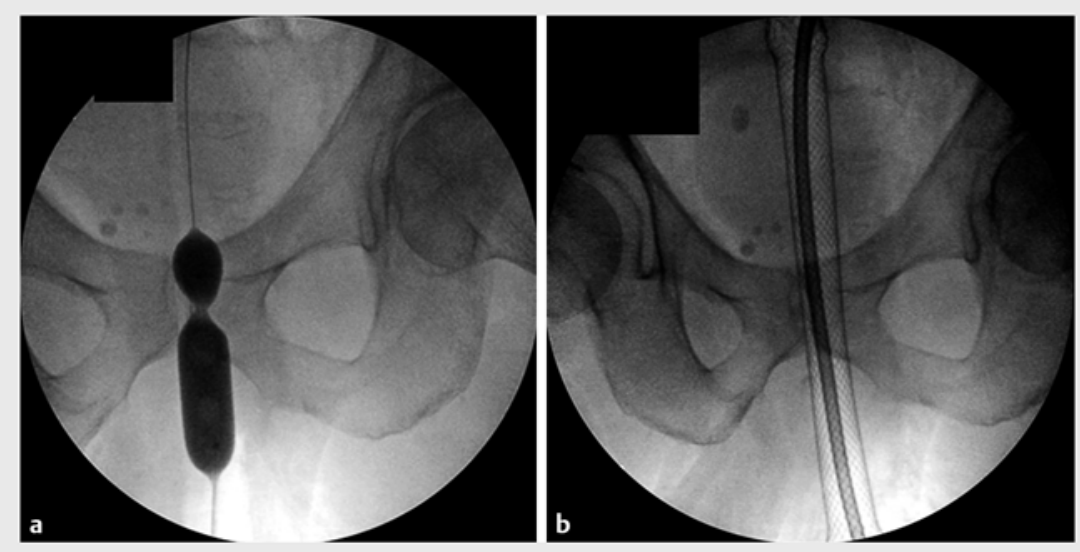

- Fig. 3 Fluoroscopic views. a Dilation of the fistulous tract and coloanal stricture using a controlled radial expansion balloon to $18 \mathrm{~mm}$. b An $18 \times 153-\mathrm{mm}$ esophageal fully covered metal stent was advanced over the guidewire from the anal side and deployed across the coloanal stricture.
The authors

Saowanee Ngamruengphong', Sonmoon Mohapatra ${ }^{2}$, Thomas M. Runge ${ }^{1}$, Eduardo Paredes $^{3}$, Sandy H. Fang ${ }^{3}$

1 Division of Gastroenterology and Hepatology, Johns Hopkins Hospital, Baltimore, Maryland, United States

2 Division of Gastroenterology and Hepatology, Saint Peter's University Hospital/Rutgers-RWJ Medical School, New Brunswick, New Jersey, United States

3 Department of Surgery, Johns Hopkins Hospital, Baltimore, Maryland, United States

\section{Corresponding author}

\section{Saowanee Ngamruengphong, MD}

Division of Gastroenterology and

Hepatology, Johns Hopkins Medicine, 4940

Eastern Avenue, A Building, 5th Floor A 501, Baltimore, MD 21224, United States

Fax: +1-410-550-3058

sngamru1@jhmi.edu

\section{Bibliography}

DOI https://doi.org/10.1055/a-1104-5119

Published online: 27.2.2020

Endoscopy 2020; 52: E312-E314

(c) Georg Thieme Verlag KG

Stuttgart · New York

ISSN 0013-726X 

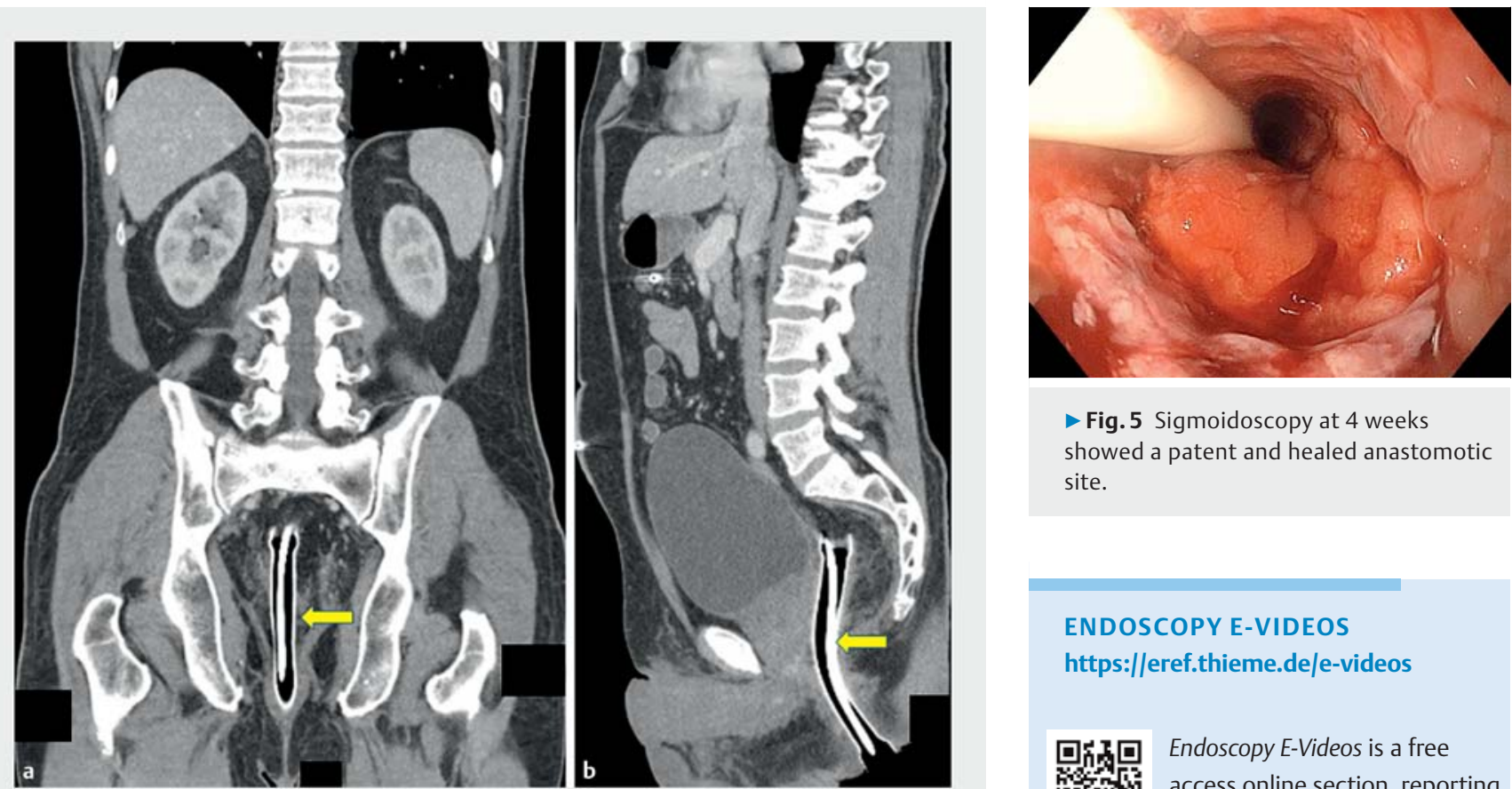

Fig. 5 Sigmoidoscopy at 4 weeks showed a patent and healed anastomotic site.

- Fig. 4 Computed tomography scans (a, b) of the abdomen/pelvis after the procedure confirmed correct stent position (arrows).

\section{ENDOSCOPY E-VIDEOS \\ https://eref.thieme.de/e-videos}

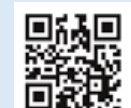

Endoscopy E-Videos is a free access online section, reporting on interesting cases and new techniques in gastroenterological endoscopy. All papers include a high quality video and all contributions are freely accessible online.

This section has its own submission website at

https://mc.manuscriptcentral.com/e-videos 